Check for updates

Cite this: RSC Adv., 2017, 7, 26559

Received 6th February 2017

Accepted 10th May 2017

DOI: 10.1039/c7ra01498h

rsc.li/rsc-advances

\section{Sensing of hydrogen peroxide and glucose in human serum via quenching fluorescence of biomolecule-stabilized Au nanoclusters assisted by the Fenton reaction $\dagger$}

\begin{abstract}
Chenghua Zong, ${ }^{a}$ Min Wang, ${ }^{a}$ Bo Li, ${ }^{a}$ Xiaojun Liu, ${ }^{a}$ Wenfeng Zhao, ${ }^{a}$ Qingquan Zhang, ${ }^{a}$ Aiye Liang ${ }^{\mathrm{b}}$ and Yang Yu (D)*a

$\mathrm{Fe}^{2+}$ can act as a catalyst to disproportionate hydrogen peroxide $\left(\mathrm{H}_{2} \mathrm{O}_{2}\right)$ to produce extremely reactive hydroxyl radicals $\left({ }^{\circ} \mathrm{OH}\right)$ through the so-called Fenton reaction. Combining this reaction with the prominent sensitive nature of gold nanoclusters ( $\mathrm{Au} \mathrm{NCs),} \mathrm{we} \mathrm{present} \mathrm{herein} \mathrm{a} \mathrm{simple} \mathrm{strategy} \mathrm{of}$ sensitive and rapid detection of $\mathrm{H}_{2} \mathrm{O}_{2}$. Compared with $\mathrm{H}_{2} \mathrm{O}_{2}$, the produced hydroxyl radical exhibits a much stronger oxidizing ability, and therefore could lead to a more efficient oxidation of the Au NCs and an improved sensitivity and oxidation rate. The results indicate that the detection limit for the determination of $\mathrm{H}_{2} \mathrm{O}_{2}$ was $0.2 \mu \mathrm{M}$ (signal/noise = 3) and the linear range was 0.4-12 $\mu \mathrm{M}$. Furthermore, in combination with the specific catalytic effect of glucose oxidase, the present sensing strategy can be successfully expanded to detect glucose in blood. The preliminary results are in good agreement with those provided by the hospital, which suggests the generalizability and great potential of the Au NCs/ Fenton hybrid system for research and clinical diagnosis of diabetes.
\end{abstract}

\section{Introduction}

Glucose, as a major energy source for living systems and metabolic intermediates, is closely associated with human health. ${ }^{1-4}$ High levels of glucose in blood can lead to diabetes, a very common disease that seriously threatens the health of human beings. For effective management of diabetes and reduction of associated complications, frequent monitoring and tight control of blood glucose levels are highly required. To date, various approaches to glucose sensing in diabetes have been actively explored. Among these methods, the optical spectrum analysis of hydrogen peroxide $\left(\mathrm{H}_{2} \mathrm{O}_{2}\right)$ produced from glucose oxidase catalysis of glucose has proved to be a popular and effective way. ${ }^{5-10}$ As one of the most reactive oxygen species, $\mathrm{H}_{2} \mathrm{O}_{2}$ is not only associated with many physiological processes but also is an important mediator in food, pharmaceutical, clinical, industrial and environmental analyses. ${ }^{11-13}$ Thus, the determination of hydrogen peroxide has also been an important task in the field of bio-imaging, healthcare and anti-terrorism. Continuing efforts in detecting $\mathrm{H}_{2} \mathrm{O}_{2}$ have been focused on

ajiangsu Key Laboratory of Green Synthesis for Functional Materials, School of Chemistry and Material Science, Jiangsu Normal University, Xuzhou, Jiangsu 221116, China

${ }^{b}$ Department of Physical Sciences, Charleston Southern University, Charleston, South Carolina, USA. E-mail: yuyang@jsnu.edu.cn; Fax:+86-516-83536266

$\dagger$ Electronic supplementary information (ESI) available. See DOI: $10.1039 / \mathrm{c} 7 \mathrm{ra} 01498 \mathrm{~h}$ different strategies including infrared/Raman spectroscopy, chromatography and electrochemical methods. ${ }^{14-16}$ Although these methods made great contributions in $\mathrm{H}_{2} \mathrm{O}_{2}$ and glucose detection, they often suffer from drawbacks, such as the requirement of expensive bulky equipment, long analysis time, complicate procedures and high detection limit. In this regard, it is still in great need of an inexpensive platform for reliable and rapid detection of $\mathrm{H}_{2} \mathrm{O}_{2}$.

$\mathrm{H}_{2} \mathrm{O}_{2}$, with an electrochemical potential of $1.77 \mathrm{v}$, can serve as an oxidizing agent. This property has been well studied and employed to control particle size and shape in the synthesis of nanomaterials. ${ }^{17-20}$ Most importantly, the prominent oxidizing nature of $\mathrm{H}_{2} \mathrm{O}_{2}$ has also been highlighted for successful development of effective $\mathrm{H}_{2} \mathrm{O}_{2}$ sensors. For example, oxidation induced dissolution of silver/gold nanoparticles ( $\mathrm{Ag} \mathrm{NPs} / \mathrm{Au} \mathrm{NPs}$ ) in the presence of $\mathrm{H}_{2} \mathrm{O}_{2}$ has been demonstrated in several kinetic and mechanistic studies. ${ }^{21-24}$ Notably, these oxidation processes often accompanied by a visible color and surface plasmon resonance (SPR) changes due to the unique size- and shape-dependent SPR properties of Ag NPs/Au NPs. Although these methods enable naked-eye detection of $\mathrm{H}_{2} \mathrm{O}_{2}$, the stabilization of $\mathrm{Ag}$ NPs/Au NPs is a challenging topic in practical application due to their easy oxidation (for Ag NPs) and aggregation. To address this issue, fluorescent quantum dots (QDs) have attracted wide attention. ${ }^{25-28}$ Comparing with the colorimetric analysis, the QDsbased fluorescent detection method exhibits more advantages, such as high sensitivity and selectivity. However, the heavy metal 
ion-containing QDs commonly suffer from intrinsic limitations, such as complicate modification, potential toxicity, intrinsic blinking and chemical instability. ${ }^{29,30}$

In order to avoid these disadvantages, we focused on goldbased nanoclusters (Au NCs). Compared to silver/gold nanoparticles and QDs, Au NCs, consisting of several to tens of gold atoms, have obvious superiority in sensing applications since they are non-toxic, high fluorescent, and have improved biocompatibility and stability. More importantly, the fluorescence of the Au NCs is highly sensitive toward sizes and changes of protecting agents. ${ }^{31,32}$ To date, various types of $\mathrm{H}_{2} \mathrm{O}_{2}$ sensors have been developed based on AuNCs. For example, Zhang has reported the first photoelectrochemical $\mathrm{H}_{2} \mathrm{O}_{2}$ sensor based on mercaptoundecanoic acid protected Au NCs (MUA-Au NCs), but it suffers from some darwbacks including limited sensitivity and poor linearity. ${ }^{33}$ Molaabasi has used haemoglobin capped $\mathrm{Au}$ NCs ( $\mathrm{Hb}-\mathrm{Au} \mathrm{NCs}$ ) for the detection of $\mathrm{H}_{2} \mathrm{O}_{2}$ by taking advantages of the sensitive nature of $\mathrm{Hb}-\mathrm{Au} \mathrm{NCs}$ and the oxidizing property of $\mathrm{H}_{2} \mathrm{O}_{2} \cdot{ }^{34}$ This method offered an improved sensitivity and linearity, however, it needed long analysis time. Besides, the blue emission of the $\mathrm{Hb}-\mathrm{Au}$ NCs may be interfered by the background autofluorescence of the serum samples. Recently, horseradish peroxidase (HRP) functioned fluorescent $\mathrm{Au}$ NCs that possess dual functions including catalysis ability and fluorescence have been designed for $\mathrm{H}_{2} \mathrm{O}_{2}$ detection. ${ }^{35}$ In this case, $\mathrm{H}_{2} \mathrm{O}_{2}$ can be catalyzed by the HRP shell, leading to a significant quenching of the fluorescent gold core. This method offers a good sensitivity and fast response, but it pose a great challenge when using in complex system such as serum, since the activity of HRP can be easily affected. By combining the prominent sensitive nature of the Au NCs with Fenton reaction, we propose herein a rapid and effective strategy for $\mathrm{H}_{2} \mathrm{O}_{2}$ and glucose detection. In the present case, $\mathrm{Fe}^{2+}$ served as a catalyst to disproportionate $\mathrm{H}_{2} \mathrm{O}_{2}$ to produce hydroxyl radical $\left({ }^{\circ} \mathrm{OH}\right)$ through the so-called Fenton reaction. ${ }^{36-38}$ The produced radical species are extremely reactive which can oxidize not only the thiol group of the protecting agent, but also the $\mathrm{Au}$ atoms in $\mathrm{Au}$ NCs. Therefore, sensitive detection of $\mathrm{H}_{2} \mathrm{O}_{2}$ can be achieved. Moreover, since the oxidizing ability of the produced radical species is much stronger than $\mathrm{H}_{2} \mathrm{O}_{2}$, the response rate could thus be significantly improved.

Compared with the known optical $\mathrm{H}_{2} \mathrm{O}_{2}$ detection strategies, our proposed method possesses some remarkable features. First, the Au NCs were fabricated with a simple, environment friendly method, thus minimizing cost and avoiding the use of toxic ions or organic reagents. Second, the fluorescence behavior of Au NCs are highly size- and surface protecting agent-dependent, hence making the present sensing strategy theoretically simple and low technical demands. In particular, the red emission of the Au NCs can decrease the interference from the background autofluorescence of the serum samples effectively. Third, the oxidizing ability of ${ }^{\circ} \mathrm{OH}$ produced from the Fenton reaction is much stronger than that of $\mathrm{H}_{2} \mathrm{O}_{2}$, and therefore affording a better sensitivity and fast response. Forth, only 100 to $200 \mu \mathrm{L}$ of serum could well meet the detection requirement owing to the high sensitivity. The whole processes could be accomplished within minutes. We believe such simple and low-cost $\mathrm{H}_{2} \mathrm{O}_{2}$ and glucose sensor has great potential in applications of point-of-care diagnostics.

\section{Experimental}

\subsection{Reagents and apparatus}

All reagents were of analytical grade and used without further purification. Ferrous sulfate $\left(\mathrm{FeSO}_{4} \cdot 7 \mathrm{H}_{2} \mathrm{O}\right), \mathrm{HAuCl}_{4} \cdot 3 \mathrm{H}_{2} \mathrm{O}$ and glucose oxidase (EC 1.1.3.4) were bought from Sigma-Aldrich. Bull Serum Albumin (BSA), hydrogen peroxide $\left(\mathrm{H}_{2} \mathrm{O}_{2}, 30\right.$ $\mathrm{wt} \%)$, sodium hydroxide $(\mathrm{NaOH})$, glucose, fructose, lactose, sucrose, maltose, mannose and other salts were purchased from Aladdin Chemical Company (Shanghai, China). Water was purified through a millipore system.

The fluorescence intensity spectra were recorded on an F-4600 fluorescence spectrometer (Hitachi Co., Japan). XPS was performed using a VGESCALAB MKII spectrometer. The XPSPEAK software was used to deconvolute the narrow-scan XPS spectra of the $\mathrm{Au} 4 \mathrm{f}$ of the Au NCs, using adventitious carbon to calibrate the C1S binding energy (284.5 eV). A PHS-3C pH (Shanghai Analytical Instrument Factory, Shanghai, China) meter was used to adjust $\mathrm{pH}$ values.

\subsection{Fluorescence detection of $\mathrm{H}_{2} \mathrm{O}_{2}$ and glucose}

The BSA-stabilized Au NCs were synthesized according to a method described in a previous report. ${ }^{39}$ Briefly, $\mathrm{HAuCl}_{4}$ solution $(5 \mathrm{~mL}, 10 \mathrm{mM})$ was added to BSA solution $(5 \mathrm{~mL}, 50 \mathrm{mg}$ $\mathrm{mL}^{-1}$ ) under vigorous stirring at $37{ }^{\circ} \mathrm{C}$. Two minutes later, $\mathrm{NaOH}$ solution $(0.5 \mathrm{~mL}, 1 \mathrm{M})$ was introduced and the reaction was allowed to proceed under vigorous stirring for $12 \mathrm{~h}$ at $37^{\circ} \mathrm{C}$. A typical $\mathrm{H}_{2} \mathrm{O}_{2}$ detection procedure by using the as-prepared $\mathrm{Au}$ NCs was conducted as follows: $50 \mu \mathrm{L}$ of as-prepared Au NCs solution were diluted by $950 \mu \mathrm{L}$ water, and then $\mathrm{HCl}$ was added to adjust the $\mathrm{pH}$ value. $8 \mu \mathrm{L} \mathrm{Fe}^{2+}(40 \mathrm{mM})$ were then added as catalysis to induce the production of radical species. Subsequently, $2 \mu \mathrm{L}$ of $\mathrm{H}_{2} \mathrm{O}_{2}$ solution with different concentrations was added to the above mixture and was incubated at room temperature for $8 \mathrm{~min}$. Finally, the fluorescence emission spectra were collected.

For glucose detection, different concentrations of glucose $(100 \mu \mathrm{L})$ were mixed with $400 \mu \mathrm{L}$ of $0.5 \mathrm{mg} \mathrm{mL}^{-1} \mathrm{GOx}$ formulated with HAc-NaAc ( $\mathrm{pH}$ 5.1) and incubated at $37{ }^{\circ} \mathrm{C}$ for an hour. Then $10 \mu \mathrm{L}$ of the mixture was added to the sensing system and incubate for $8 \mathrm{~min}$. The fluorescence intensities were recorded in the wavelength range of 550-800 $\mathrm{nm}$.

The selectivity of the sensing system toward glucose was evaluated by using sucrose, mannose, cellobiose, lactose, fructose, maltose, folic acid and typisn. Moreover, the selectivity of the sensing system toward common cations $\left(\right.$ e.g. $, \mathrm{K}^{+}, \mathrm{Ca}^{2+}, \mathrm{Mg}^{2+}$, $\mathrm{Zn}^{2+}$ and $\mathrm{Cu}^{2+}$ ) was also evaluated by using their corresponding nitrates. In the case of $\mathrm{Cu}^{2+}$, polyethyleneimine (PEI, $M_{\mathrm{w}}=$ 25000 ) was used to chelate and separate $\mathrm{Cu}^{2+}$.

The procedure for glucose detection in serum was as follows: human serum samples were obtained from healthy volunteers treated in local hospital. The samples were centrifuged at $12000 \mathrm{rpm}$ for $10 \mathrm{~min}$ to remove the possible interference of 
proteins in human serum. $100 \mu \mathrm{L}$ of serum samples and $400 \mu \mathrm{L}$ of $0.5 \mathrm{mg} \mathrm{mL}^{-1} \mathrm{GOx}$ were incubated at $37^{\circ} \mathrm{C}$ for an hour. Then $10 \mu \mathrm{L}$ of the above mixture was added to the Au NCs sensing system as mentioned above and incubate for $8 \mathrm{~min}$. Finally, the fluorescence intensity was collected at room temperature. All fluorescence detections were performed under the same conditions.

\subsection{Live subject statement}

The author state that the blood related experiments were performed in strict accordance with the WHO guidelines on blood drawing (WHO Publication ISBN-13: 978-92-4-159922-1, 2010) and was approved by Jiangsu Normal University. The authors also state that informed consent was obtained for any experimentation with human subjects and the Jiangsu Normal University is committed to the protection and safety of human subjects involved in research.

\section{Results and discussion}

\subsection{Mechanism for fluorescence quenching of Au NCs}

Bovine serum albumin (BSA) stabilized Au NCs were prepared according to a method described previously. ${ }^{39}$ Transmission electron microscopy (TEM) images reveal that the as-prepared $\mathrm{Au}$ NCs have an average diameter of $c a .1 .2 \mathrm{~nm}$ (Fig. S1 $\dagger$ ). As shown in Fig. 1A, the initial solution of the as-prepared Au NCs exhibited a bright red fluorescence with the maximum emission spectra centered at $660 \mathrm{~nm}$ upon excitation at $529 \mathrm{~nm}$. It is well known that $\mathrm{H}_{2} \mathrm{O}_{2}$ can generate extremely oxidative hydroxyl radicals in the presence of $\mathrm{Fe}^{2+}$, so called Fenton reaction, which has been widely applied in wastewater treatment. ${ }^{36}$ Herein, we take advantage of Fenton reaction to accelerate fluorescence quenching of Au NCs in the presence of $\mathrm{H}_{2} \mathrm{O}_{2}$ to sensitive and selective detect $\mathrm{H}_{2} \mathrm{O}_{2}$ and glucose (Scheme 1). After $20 \mu \mathrm{M} \mathrm{H}_{2} \mathrm{O}_{2}$ was added to the Au NCs- $\mathrm{Fe}^{2+}-\mathrm{HCl}$ system, the corresponding emission intensity of the sensing system was completely quenched (Fig. 1A). Notably, this quenching efficiency was much larger than that of $\mathrm{H}_{2} \mathrm{O}_{2}$. Dong et al. reported that $0.5 \mathrm{mM} \mathrm{H}_{2} \mathrm{O}_{2}$ could induce $45 \%$ quenching of the fluorescence of $\mathrm{Au}$ NCs in $30 \mathrm{~min} .{ }^{40}$ Impressively, our experiments showed that $10 \mu \mathrm{M} \mathrm{H}_{2} \mathrm{O}_{2}$ could reduce $76 \%$ of the fluorescence of Au NCs within $8 \mathrm{~min}$. This increased quenching efficiency was reasonable considering the fact that the oxidizing ability of $\cdot \mathrm{OH}$ produced from Fenton reaction is much stronger than that of $\mathrm{H}_{2} \mathrm{O}_{2}$. Therefore, ${ }^{\circ} \mathrm{OH}$ could lead to a more efficient
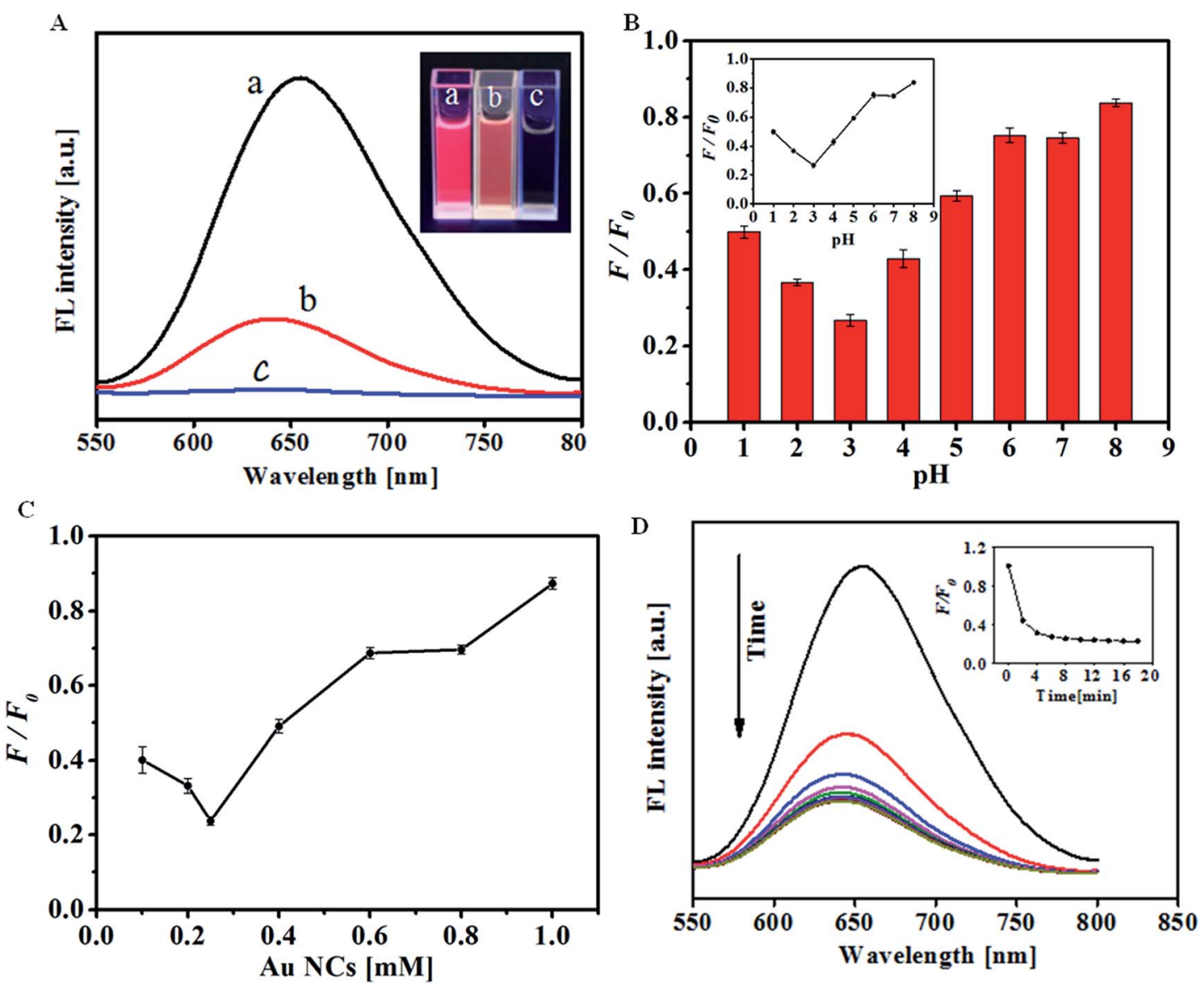

Fig. 1 (A) Fluorescence response of the Au NCs in the absence (a) and presence of $10 \mu \mathrm{M} \mathrm{H}_{2} \mathrm{O}_{2}$ (b) and $20 \mu M \mathrm{H}_{2} \mathrm{O}_{2}$ (c) respectively; (B) fluorescence response of the Au NCs toward $10 \mu \mathrm{M} \mathrm{H}_{2} \mathrm{O}_{2}$ at different $\mathrm{pH}$ values; (C) relationship between $F / F_{0}$ and the concentration of Au NCs in the presence of $10 \mu \mathrm{M} \mathrm{H}_{2} \mathrm{O}_{2}$; (D) time-dependent fluorescence response of the Au NCs to10 $\mu \mathrm{M} \mathrm{H}_{2} \mathrm{O}_{2}\left(F_{0}\right.$ and $F$ are the fluorescence intensity of the $\mathrm{H}_{2} \mathrm{O}_{2}$ at $660 \mathrm{~nm}$ in the absence and presence of $\mathrm{H}_{2} \mathrm{O}_{2}$, respectively). 


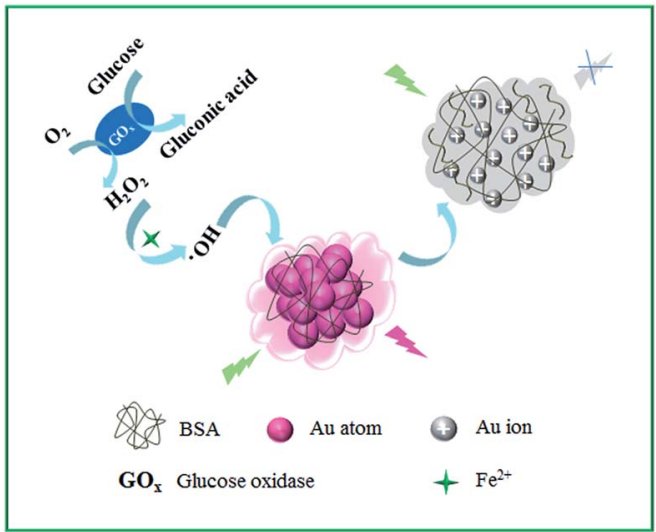

Scheme 1 Principle representation of the developed method for $\mathrm{H}_{2} \mathrm{O}_{2}$ and glucose sensing.

quenching of the Au NCs and provide an improved sensitivity and oxidation rate. To understand the origin of the outstanding sensing performance of the present sensing system toward $\mathrm{H}_{2} \mathrm{O}_{2}$, possible interactions between $\mathrm{Au}$ NCs and $\mathrm{H}_{2} \mathrm{O}_{2}$ in the presence of $\mathrm{Fe}^{2+}$ were further investigated by X-ray photoelectron spectroscopy (XPS) analysis. For the as-prepared Au NCs, the $\mathrm{Au} 4 \mathrm{f}_{7 / 2}$ peak in the XPS spectrum at $83.7 \mathrm{eV}$ is in good agreement with previous literature value. ${ }^{41}$ Whereas, this peak shifted to a higher binding energy $(84.7 \mathrm{eV})$ upon the addition of $\mathrm{H}_{2} \mathrm{O}_{2}$ (Fig. S2 $\dagger$ ), which indicated the oxidation of the $\mathrm{Au}$ atoms in $\mathrm{Au}$ NCs. ${ }^{42}$ Besides, previous studies have confirmed that $\mathrm{Au}-\mathrm{S}$ bond can be degraded in the presence of $\mathrm{H}_{2} \mathrm{O}_{2}$ as an oxidant to form disulfides and sulfonates which can be easily removed from the Au surface. ${ }^{40,43}$ Considering the above facts and the stronger oxidizing ability of ${ }^{\circ} \mathrm{OH}$, it is reasonable to believe that oxidation of the Au-S bond may also occur during the $\mathrm{H}_{2} \mathrm{O}_{2}$ recognition process. To verify this assumption, the absorption spectra of the Au NCs in the presence and absence of $\mathrm{H}_{2} \mathrm{O}_{2}$ were recorded, respectively. As shown in Fig. S3, $\dagger$ the original Au NCs exhibited a characteristic absorbance at $278 \mathrm{~nm}$, which mainly originates from the aromatic residues and disulfide bonds in BSA, the stabilizing protein in Au NCs. ${ }^{44}$ However, this peak shifted distinctly in the presence of $10 \mu \mathrm{M} \mathrm{H}_{2} \mathrm{O}_{2}$, which could be assigned to the oxidation of the composition of BSA as suggested by previous reports. ${ }^{40,45}$ The above results clearly indicated that both the protecting BSA molecule and the Au atoms were oxidized during the course of $\mathrm{H}_{2} \mathrm{O}_{2}$ response. Thus, it is reasonable to conclude that the effective fluorescence quenching of the sensing system in the presence of $\mathrm{H}_{2} \mathrm{O}_{2}$ could ascribe to the oxidation-induced destruction of the Au NCs.

\subsection{Optimization of the sensing parameters and detection of $\mathrm{H}_{2} \mathrm{O}_{2}$}

It is known that the catalytic decomposition of $\mathrm{H}_{2} \mathrm{O}_{2}$ by $\mathrm{Fe}^{2+}$ depends on the $\mathrm{pH}$ value of the reaction media. In order to achieve sensitive detection of $\mathrm{H}_{2} \mathrm{O}_{2}$ and glucose, effect of the $\mathrm{pH}$ value on the fluorescence response of $\mathrm{H}_{2} \mathrm{O}_{2}$ was studied and optimized. According to previous reports, the Fenton reaction is more favored in acidic medium ${ }^{36}$ and thus, $\mathrm{pH}$ value higher than 8.0 was not considered. Fig. 1B shows the quenching efficiency as a function of $\mathrm{pH}$ value. In the studied $\mathrm{pH}$ range of 1.0-8.0, the quenching efficiency of the sensing system in the presence of $\mathrm{H}_{2} \mathrm{O}_{2}$ was gradually increased with increasing $\mathrm{pH}$ from 1 to 3 , reached the maximum at $\mathrm{pH}$ 3.0, and then gradually decreased at higher $\mathrm{pH}(4-8)$. Based on the above results, $\mathrm{pH} 3.0$ was chosen for further determination assays. Furthermore, the quenching efficiency of $\mathrm{H}_{2} \mathrm{O}_{2}$ in the presence of $\mathrm{Fe}^{2+}$ as a function of the concentration of Au NCs was assessed. It was found that the fluorescence quenching is more efficient at lower concentration of the fluorescence probe (Fig. 1C) in the presence of a given concentration of $\mathrm{H}_{2} \mathrm{O}_{2}$. In the present case, $0.25 \mathrm{mM}$ Au NCs was selected for the subsequent experiments. Moreover, to quantify the response rate of the sensing system, the time dependent fluorescence response of the sensing system to $10 \mu \mathrm{M} \mathrm{H}_{2} \mathrm{O}_{2}$ was monitored at $660 \mathrm{~nm}$ with an excitation wavelength of $529 \mathrm{~nm}$ (Fig. 1D). The curve shows a rapid decrease of the fluorescence intensity in the first $6 \mathrm{~min}$, and kept almost unchanged after $8 \mathrm{~min}$, which suggests that $8 \mathrm{~min}$ is enough for the detection of $\mathrm{H}_{2} \mathrm{O}_{2}$.
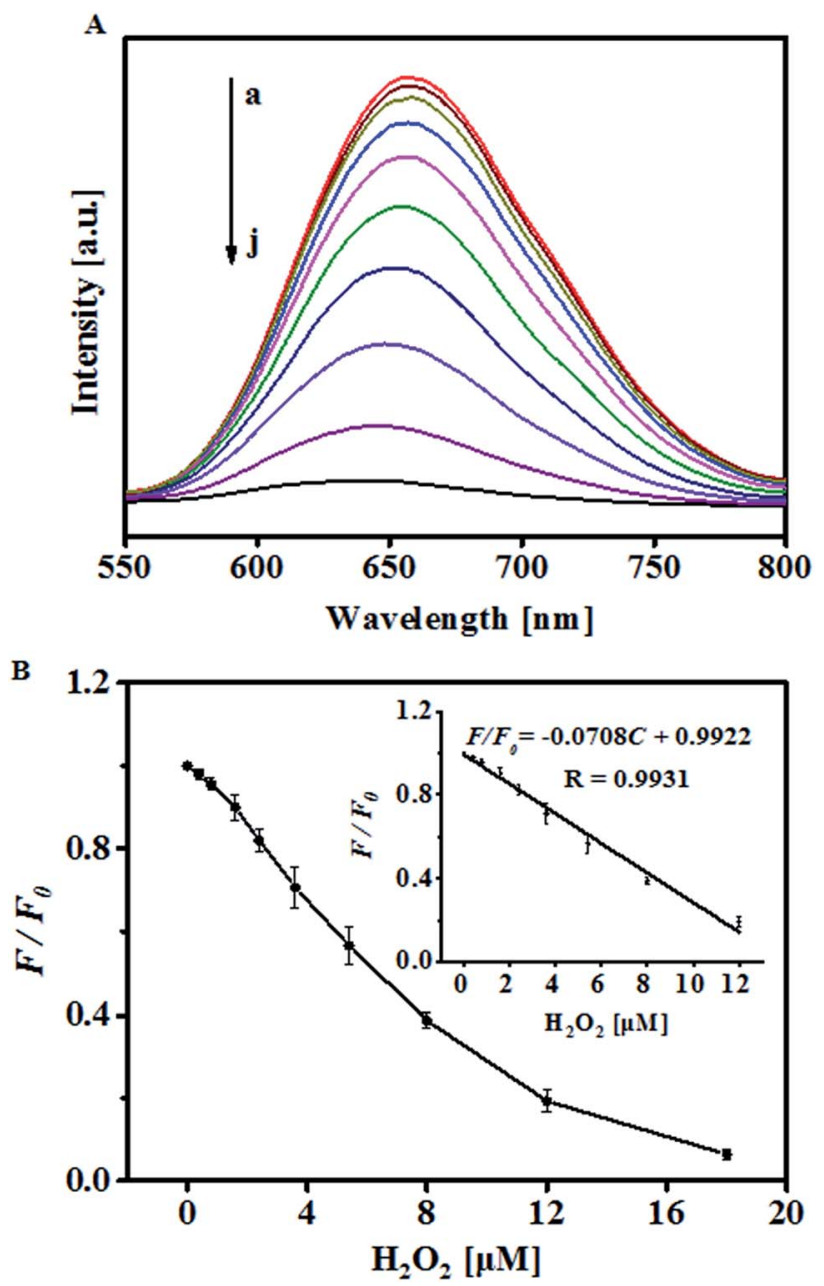

Fig. 2 (A) Fluorescence response of the Au NCs upon addition of various concentrations of $\mathrm{H}_{2} \mathrm{O}_{2}$ at a $\mathrm{pH}$ value of $3\left(\mathrm{H}_{2} \mathrm{O}_{2}\right.$ concentrations from a to $(\mu \mathrm{M})$ : $0 ; 0.4 ; 0.8 ; 1.6 ; 2.4 ; 3.6 ; 5.4 ; 8 ; 12$ and 18$)$; $(B)$ the relationship between $F / F_{0}$ and the concentration of $\mathrm{H}_{2} \mathrm{O}_{2}$. The inset is the linear plot in the range of 0 to $12 \mu \mathrm{M} \mathrm{H}_{2} \mathrm{O}_{2}$. 
Under the optimized conditions, the capability of the proposed strategy to sensitively and selectively detect $\mathrm{H}_{2} \mathrm{O}_{2}$ was evaluated. Plotting $F / F_{0}$ ( $F_{0}$ and $F$ refer to the fluorescence intensity of the sensing system in the absence and presence of $\mathrm{H}_{2} \mathrm{O}_{2}$, respectively) as a function of $\mathrm{H}_{2} \mathrm{O}_{2}$ concentration shows a good linear relationship over the concentration range from 0.4 to $12 \mu \mathrm{M}$, which clearly validates the sensing performance of the proposed strategy toward $\mathrm{H}_{2} \mathrm{O}_{2}$ (Fig. 2). The limit of the detection for $\mathrm{H}_{2} \mathrm{O}_{2}$, at a signal-to-noise ratio of 3 , is $0.2 \mu \mathrm{M}$, which is lower than some other optical methods (Table $\mathrm{S} 1 \dagger$ ). The percent relative standard deviation was $3.32 \%$ with five replicate detections of $10 \mu \mathrm{M} \mathrm{H}_{2} \mathrm{O}_{2}$ (Table $\mathrm{S} 2 \dagger$ ), which indicated a good reproducibility of the present method.

\subsection{Glucose sensing based on the Au NCs/Fenton and glucose oxidase system}

Considering that GOx can catalyze the oxidation of glucose to produce $\mathrm{H}_{2} \mathrm{O}_{2}$, the successful sensitive detection of $\mathrm{H}_{2} \mathrm{O}_{2}$ was, then, implemented for the analysis of glucose. The process for detecting glucose includes two steps: firstly, $\mathrm{H}_{2} \mathrm{O}_{2}$ is generated from the biocatalyzed reaction between varied concentration of glucose and excess amount of GOx. Secondly, a certain volume of the resulted mixture was introduced into the sensing system for $8 \mathrm{~min}$ and then the corresponding fluorescence spectra were measured. Fig. 3 displays that the fluorescence intensity of $\mathrm{Au}$ NCs reduced gradually with increasing concentration of glucose. Controlled experiments showed that $\mathrm{O}_{2}$, glucose oxidase, and glucose were all essential to the quenching of Au NCs (Fig. 3A inset) since the exclusion of either component would yield no $\mathrm{H}_{2} \mathrm{O}_{2}$. After optimizing the experimental parameters, a linear calibration curve is achieved by plotting $F / F_{0}$ versus glucose concentration in the range of $2-60 \mu \mathrm{M}$ (Fig. 3B). A detection limit of $0.8 \mu \mathrm{M}$ was calculated from the equation ( $\operatorname{signal} /$ noise $=3$ ). To investigate whether this sensing system is specific for glucose detection, the effect of some other carbohydrates and metal ions

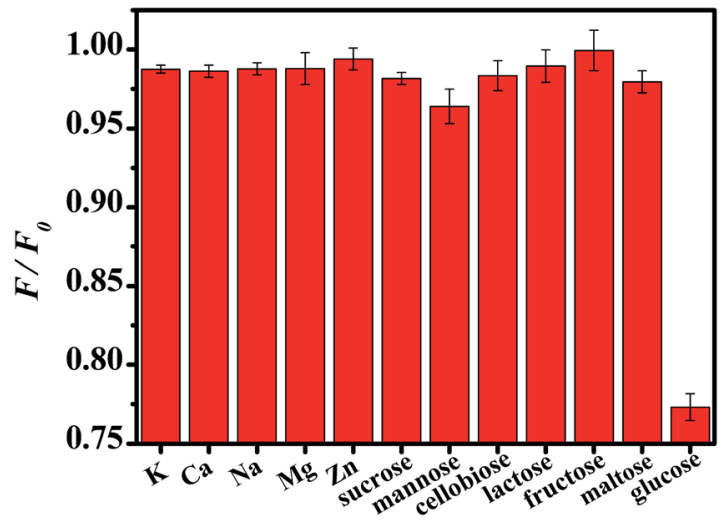

Fig. 4 The relative fluorescence intensity of the Au NCs in the presence of $10 \mu \mathrm{M}$ various carbohydrates and some metal ions commonly exist in serum.

that commonly present in human blood on the fluorescence of the sensing system were evaluated under the optimum conditions. As demonstrated in Fig. 4, the addition of glucose could induce a significant quenching of the Au NCs fluorescence due to the high substrate specificity of GOx. However, other carbohydrates and metal ions had a negligible effect under the identical conditions. Considering that trypsin, folic acid (FA) and $\mathrm{Cu}^{2+}$ were reported to quench the fluorescence of the Au NCs, ${ }^{46-49}$ thus, the fluorescence response of our sensing system towards these substance were further examined. As shown in Fig. S4, $\uparrow$ no obvious fluorescence change was observed even in the presence of high concentrations of trypsin and FA. This results is explainable since the low $\mathrm{pH}$ condition $(\mathrm{pH}=3.0)$ selected in our system can not only weaken the interaction between FA and BSA via protonating both of them but also denature the trypsin. Also, it is noted that $\mathrm{Cu}^{2+}$ with high concentration do have an effect on the fluorescence intensity of the BSA-Au NCs as reported by Lin, ${ }^{48}$ but such interference could be evaded by adding polyethyleneimine
A

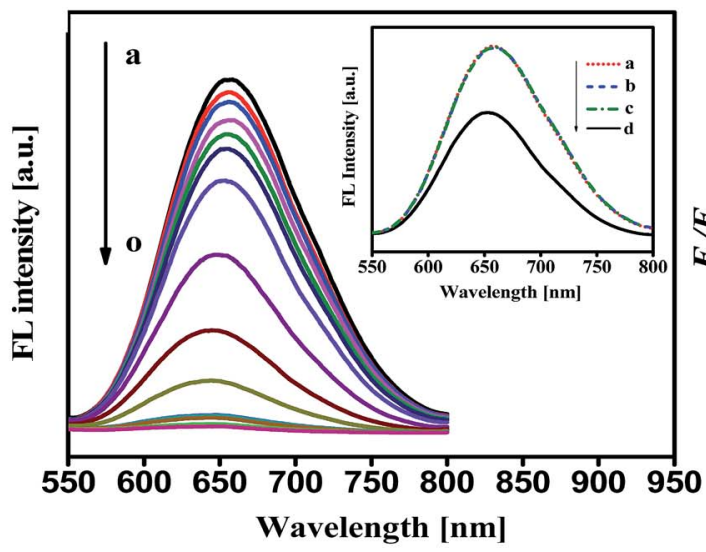

B

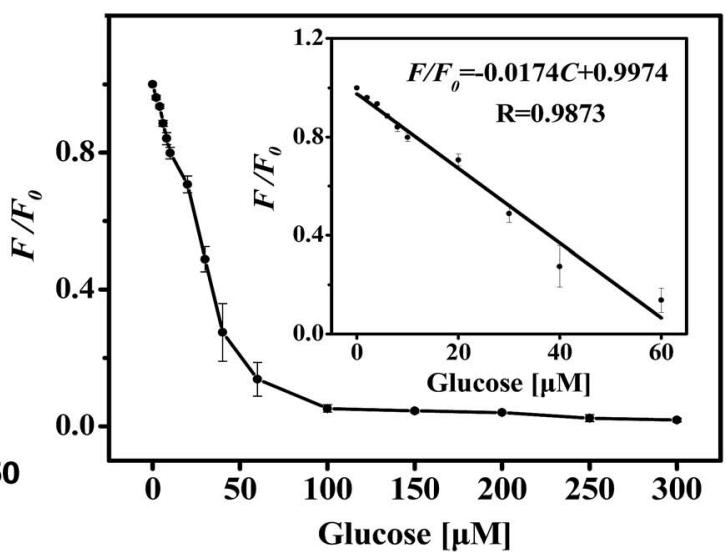

Fig. 3 (A) Fluorescence spectra represent the quenching effect of glucose-GOx system with different glucose concentrations on the fluorescence of $A u N C s$, glucose concentration from a to o $(\mu \mathrm{M})$ : $0 ; 2 ; 4 ; 6 ; 8 ; 10 ; 20 ; 30 ; 40 ; 60 ; 100 ; 150 ; 200 ; 250 ; 300$. Inset: fluorescence spectra of Au NCs (a); Au NCs with glucose oxidase $\left(0.4 \mathrm{mg} \mathrm{L}^{-1}\right)$ (b); Au NCs with glucose (20 $\left.\mu \mathrm{M}\right)$ (c); Au NCs with glucose $(20 \mu \mathrm{M})$ and glucose oxidase $\left(0.4 \mathrm{mg} \mathrm{L}^{-1}\right)(\mathrm{d})$; (B) the relationship between $F / F_{0}$ and the concentration of glucose. The inset is the linear plot in the range of 0 to $60 \mu \mathrm{M}$ glucose. 
Table 1 Analytical results of glucose in serum samples

\begin{tabular}{llll}
\hline Sample no. & $\begin{array}{l}\text { Local hospital } \\
(\mathrm{mM})\end{array}$ & $\begin{array}{l}\text { Proposed method } \\
(\mathrm{mM})\end{array}$ & $\begin{array}{l}\text { Relative deviation } \\
(\%)\end{array}$ \\
\hline 1 & 4.59 & 4.65 & 1.30 \\
2 & 4.96 & 4.86 & -2.02 \\
3 & 5.25 & 5.34 & 1.71 \\
4 & 12.59 & 12.12 & -3.73 \\
5 & 5.09 & 4.94 & -2.95 \\
\hline
\end{tabular}

(PEI) as scavengers (Fig. S4c $\dagger$ ). Therefore, sensitive and selective detection of glucose can be achieved through our proposed method. Moreover, comparable fluorescence response toward 10 $\mu \mathrm{M} \mathrm{H}_{2} \mathrm{O}_{2}$ were performed by using Au NCs stored at $4{ }^{\circ} \mathrm{C}$ for one and two weeks, respectively. The negligible change (the percent relative standard deviation is $2.76 \%$ ) of the fluorescence response as presented in Table $\mathrm{S} 3 \dagger$ indicated the good stability and reproducibility of our sensing system. Due to the above merits, the present method is expected to have a general applicability for detecting glucose in blood.

\subsection{Determination of glucose in real serum samples}

Glucose levels in blood are associated closely with diabetes or hypoglycemia. Thus it is of great importance to accurately monitor blood glucose levels for diagnosis and management of diabetes. Encouraged by the above promising results, the sensing system was further applied to monitor glucose in real serum samples. In this case, the fresh human serum samples were obtained from a local hospital and used as testing samples after simple centrifugation treatment. Taking into consideration of the normal fasting blood glucose (FBG) level in the healthy human blood (3.9-6.1 $\mathrm{mmol} \mathrm{L}^{-1}$ ) as well as the linear range of our method, $100 \mu \mathrm{L}$ of serum should well meet onetime glucose measurement. In a proof of concept experiment, $100 \mu \mathrm{L}$ of the testing samples were firstly incubated with $400 \mu \mathrm{L}$ GOx $\left(0.5 \mathrm{mg} \mathrm{mL}^{-1}\right)$ for an hour, then $10 \mu \mathrm{L}$ of the resulted mixture was added to the sensing system $(1 \mathrm{~mL})$ and the fluorescence spectra were measured. It is worthy to note that the serum samples were 500 -fold diluted during the process and therefore, the possible interference from the serum matrix could be significantly reduced. The concentrations of the clinical samples were calculated from the standard curve and the regression equation. Impressively, the glucose concentration obtained by our method is in good agreement with those provided by the hospital (Table 1), which further confirms the general applicability of the proposed method for the analysis of glucose in real physiological clinical samples.

\section{Conclusion}

By combining the Fenton reaction with the prominent sensitive nature of the Au NCs, a rapid, highly sensitive, selective, and cost-efficient sensing approach for $\mathrm{H}_{2} \mathrm{O}_{2}$ and glucose detection has been designed. The sensing approach was successfully applied to monitor glucose levels in human serum with satisfactory results. The sensing strategy proposed in this study is very promising in pharmaceutical and clinical detection of $\mathrm{H}_{2} \mathrm{O}_{2}$ and glucose due to the advantages of easy fabrication and operation. We anticipate that the designed strategy can also be extended to the detection of various $\mathrm{H}_{2} \mathrm{O}_{2}$-involved analytes. This may open up a new avenue in developing low-cost and sensitive method for biological and clinical diagnostics application.

\section{Acknowledgements}

The authors would like to acknowledge the financial support from the Natural Science Foundation of China (NSFC 21601072), Natural Science Foundation of Jiangsu Province (BK20150228), Natural Science Foundation of the Higher Education Institutions of Jiangsu Province (16KJA150006) and Priority Academic Program Development of Jiangsu Higher Education Institutions.

\section{References}

1 M. A. Pleitez, T. Lieblein, A. Bauer, O. Hertzberg, H. von Lilienfeld-Toal and W. Mantele, Anal. Chem., 2013, 85, 1013-1020.

2 Y. Ling, N. Zhang, F. Qu, T. Wen, Z. F. Gao, N. B. Li and H. Q. Luo, Spectrochim. Acta, Part A, 2014, 118, 315-320.

3 Y. Yi, J. Deng, Y. Zhang, H. Li and S. Yao, Chem. Commun., 2013, 49, 612-614.

4 H. B. Wang, H. D. Zhang, Y. Chen, Y. Li and T. Gan, RSC Adv., 2015, 5, 77906-77912.

5 L. Wang, J. Zheng, Y. Li, S. Yang, C. Liu, Y. Xiao, J. Li, Z. Cao and R. Yang, Anal. Chem., 2014, 86, 12348-12354.

6 O. S. Wolfbeis, A. Durkop, M. Wu and Z. H. Lin, Angew. Chem., Int. Ed., 2002, 41, 4495-4498.

7 S. Chen, X. Hai, X. W. Chen and J. H. Wang, Anal. Chem., 2014, 86, 6689-6694.

8 L. P. Lin, X. H. Song, Y. Y. Chen, M. C. Rong, T. T. Zhao, Y. R. Wang, Y. Q. Jiang and X. Chen, Anal. Chim. Acta, 2015, 869, 89-95.

9 L. Z. Hu, Y. L. Yuan, L. Zhang, J. M. Zhao, S. Majeed and G. B. Xu, Anal. Chim. Acta, 2013, 762, 83-86.

10 H. B. Wang, Y. Chen, N. Li and Y. M. Liu, Microchim. Acta, 2017, 184, 515-523.

11 D. J. Rossi, C. H. M. Jamieson and I. L. Weissman, Cell, 2008, 132, 681-696.

12 N. E. Sharpless and R. A. Depinho, Nat. Rev. Mol. Cell Biol., 2007, 8, 703-713.

13 D. Srikun, A. E. Albers, C. I. Nam, A. T. Iavaron and C. J. Chang, J. Am. Chem. Soc., 2010, 132, 4455-4465.

14 W. Chen, S. Cai, Q.-Q. Ren, W. Wen and Y.-D. Zhao, Analyst, 2012, 137, 49-58.

15 T. H. Huang, M. E. Garceau and P. Gao, J. Pharm. Biomed. Anal., 2003, 31, 1203-1210.

16 L. L. Qu, Y. Y. Liu, S. H. He, J. Q. Chen, Y. Liang and H. T. Li, Biosens. Bioelectron., 2016, 77, 292-298.

17 W. Ni, X. Kou, Z. Yang and J. Wang, ACS Nano, 2008, 2, 677686. 
18 M. Tsuji, S. Gomi, Y. Maeda, M. Matsunaga, S. Hikino, K. Uto, T. Tsuji and H. Kawazumi, Langmuir, 2012, 28, 8845-8861.

19 Q. Zhang, C. M. Cobley, J. Zeng, L. P. Wen, J. Y. Chen and Y. N. Xia, J. Phys. Chem. C, 2010, 114, 6396-6400.

20 Q. Zhang, N. Li, J. Goebl, Z. Lu and Y. Yin, J. Am. Chem. Soc., 2011, 133, 18931-18939.

21 K. Nitinaivinij, T. Parnklang, C. Thammacharoen, S. Ekgasit and K. Wongravee, Anal. Methods, 2014, 6, 9816-9824.

22 Y. Xia, J. Ye, K. Tan, J. Wang and G. Yang, Anal. Chem., 2013, 85, 6241-6247.

23 X. M. Ma, Z. T. Chen, P. Kannan, Z. Y. Lin, B. Qiu and L. H. Guo, Anal. Chem., 2016, 88, 3227-3234.

24 G. Y. Shan, S. J. Zheng, S. P. Chen, Y. W. Chen and Y. C. Liu, Colloids Surf., B, 2013, 102, 327-330.

25 R. Gill, L. Bahshi, R. Freeman and I. Willner, Angew. Chem., Int. Ed., 2008, 47, 1676-1679.

26 L. H. Cao, J. Ye, L. L. Tong and B. Tang, Chem.-Eur. J., 2008, 14, 9633-9640.

27 M. Hu, J. Tian, H. T. Lu, L. X. Weng and L. H. Wang, Talanta, 2010, 82, 997-1002.

28 J. J. Ge, X. L. Ren, X. Z. Qiu, H. T. Shi, X. W. Meng and F. Q. Tang, J. Mater. Chem. B, 2015, 3, 6385-6390.

29 A. M. Derfus, W. C. W. Chan and S. N. Bhatia, Nano Lett., 2004, 4, 11-18.

30 S. F. Lee and M. A. Osborne, J. Am. Chem. Soc., 2007, 129, 8936-8937.

31 P. C. Chen, A. P. Periasamy, S. G. Harroun, W. P. Wu and H. T. Chang, Coord. Chem. Rev., 2016, 320, 129-138.

32 L. Y. Chen, C. W. Wang, Z. Q. Yuan and H. T. Chang, Anal. Chem., 2015, 87, 216-229.

33 J. Zhang, L. Tu, S. Zhao, G. Liu, Y. Wang, Y. Wang and Z. Yue, Biosens. Bioelectron., 2015, 67, 296-302.
34 F. Molaabasi, S. Hosseinkhani, A. A. Moosavi-Movahedi and M. Shamsipu, RSC Adv., 2015, 5, 33123-33135.

35 F. Wen, Y. Dong, L. Feng, S. Wang, S. Zhang and X. Zhang, Anal. Chem., 2011, 83, 1193-1196.

36 E. F. Olasehinde, S. Makino, H. Kondo, K. Takeda and H. Sakugawa, Anal. Chim. Acta, 2008, 627, 270-276.

37 H. H. Deng, G. W. Wu, D. He, H. P. Peng, A. L. Liu, X. H. Xia and W. Chen, Analyst, 2015, 140, 7650-7656.

38 L. Zhang, R. P. Liang, S. J. Xiao, J. M. Bai, L. L. Zheng, L. Zhan, X. J. Zhao, J. D. Qiu and C. Z. Huang, Talanta, 2014, 118, 339-347.

39 J. P. Xie, Y. G. Zheng and J. Y. Ying, J. Am. Chem. Soc., 2009, 131, 888-890.

40 L. H. Jin, L. Shang, S. J. Guo, Y. X. Fang, D. Wen, L. Wang, J. Y. Yin and S. J. Dong, Biosens. Bioelectron., 2011, 26, 1965-1969.

41 M. Brust, M. Walker, D. Bethell, D. J. Schiffrin and R. Whyman, J. Chem. Soc., Chem. Commun., 1994, 801-802, DOI: $10.1039 / \mathrm{c} 39940000801$.

42 M. Dasog and R. W. J. Scott, Langmuir, 2007, 23, 3381-3387.

43 C. Vericat, M. E. Vela, G. Benitez, P. Carro and R. C. Salvarezza, Chem. Soc. Rev., 2010, 39, 1805-1834.

44 L. Shang, Y. Z. Wang, J. G. Jiang and S. J. Dong, Langmuir, 2007, 23, 2714-2721.

45 D. Y. Luo, S. W. Smith and B. D. Anderson, J. Pharm. Sci., 2005, 94, 304-316.

46 B. Hemmateenejad, F. Shakerizadeh-shirazi and F. Samari, Sens. Actuators, B, 2014, 199, 42-46.

47 L. Hu, S. Han, S. Parveen, Y. Yuan, L. Zhang and G. Xu, Biosens. Bioelectron., 2012, 32, 297-299.

48 Z. Lin, F. Luo, T. Dong, L. Zheng, Y. Wang, Y. Chi and G. Chen, Analyst, 2012, 137, 2394-2399.

49 Y. Tao, Y. Lin, J. Ren and X. Qu, Biosens. Bioelectron., 2013, 42, 41-46. 